\title{
Optional or Obligatory? Exploring Undergraduate University Students' Attitudes, Opinions, and Beliefs Around Verbal Sexual Consent
}

\author{
Brittany A. Matchett ${ }^{1}$, BSc, and Matthew S. Numer ${ }^{1}, \mathrm{PhD}$ \\ ${ }^{1}$ Faculty of Health and Human Performance, Dalhousie University
}

DOI: https://doi.org/10.15273/hpj.v1i2.10658

\begin{abstract}
Introduction: For the last 20 years, sexual assault on university campuses has occurred at epidemic levels. This may be caused by undergraduate students primarily using non-verbal cues to communicate sexual consent, despite high levels of miscommunication and misinterpretation. Explicit, verbalized consent is known to lead to fewer misinterpretations of consent; however, less is known about students' beliefs around verbal consent. Objectives: To explore Canadian undergraduate students' attitudes, opinions, and beliefs around verbal consent, and to investigate whether students believe verbal consent is always required during sexual encounters. Methods: This study used a qualitative description approach. Data was collected from 31 Canadian undergraduate students in a Human Sexuality course through an open-ended question embedded in an interactive course textbook. Students' responses were analyzed using thematic analysis. Results: Many complexities exist in undergraduate students' attitudes, opinions, and beliefs around verbal consent. Four major themes emerged from the data centring on familiarity, socio-cultural norms, reliance on non-verbal cues, and acknowledgement of the importance of verbal consent. Conclusion: The majority of participants believed that verbal consent was not required in all sexual encounters. Partner familiarity was a significant factor in using verbal consent. Social norms such as verbal consent being viewed as awkward or embarrassing were key barriers to students' use. Verbal consent was viewed as an ideal, while non-verbal consent was viewed as realistic.
\end{abstract}




\section{Optional or Obligatory? Exploring Undergraduate University Students' Attitudes, Opinions, and Beliefs Around Verbal Sexual Consent}

University campuses have been identified as one of the most prevalent settings where sexual assault (SA) occurs (Quinlan et al., 2016). The Criminal Code (1985, c. C-46, s. 271.1 [1]) describes SA as "an assault committed in circumstances of a sexual nature such that the sexual integrity of the victim is violated." SA occurs when sexual consent is lacking in sexual encounters. According to the Criminal Code of Canada (1985, c. C-46, s. 273.1 [1]), sexual consent is defined as "the voluntary agreement to engage in the sexual activity in question." University students are significantly more likely to experience SA compared to the general population (Marcantonio et al., 2018; Pugh \& Becker, 2018; Senn et al., 2014). Research has found that one in four women enrolled in a North American university will experience some form of sexualized violence (Senn et al., 2014). $\mathrm{SA}$ is rooted in gender inequality and is a persistent form of gender-based violence that continues to marginalize, harm, and disempower women in society (World Health Organization, 2012). Achieving gender equality is one of the United Nations' sustainable development goals (United Nations, n.d.). However, rates of SA on university campuses remain at epidemic levels (Potter et al., 2018; Senn et al., 2014).

University campuses perpetuate an environment that is conducive to SA due to complex socio-cultural norms, including high levels of hypermasculine norms, high levels of rape myth acceptance, and reliance on nonverbal consent (Jozowski et al., 2014). SA is inextricably linked to consent, as sexual consent is the differentiating factor between consensual and non-consensual sexual activity (Jozkowski \& Peterson, 2013). Universities have begun emphasizing explicit verbal consent as the standard for obtaining sexual consent (Curtis \& Burnett, 2017). The need for verbal consent has been highlighted in prior research showing that non-verbal consent contributes to high rates of
SA (Hermann et al., 2018). Despite this, virtually no research to date has been conducted specifically examining undergraduate (UG) students' beliefs around verbal consent. Additionally, most of the research on sexual consent has been focused on American students, causing the experiences of Canadian students to be less well understood. This is concerning, as Canadian students are believed to be more at risk of experiencing SA than American students (Daigle et al., 2019). To address the gaps in the literature, the purpose of this study was to explore the attitudes, opinions, and beliefs around verbal consent among Canadian UG students. The purpose of this study was addressed through the following research questions:

a) What are the current attitudes, opinions, and beliefs of undergraduate students enrolled in a Canadian university around verbal consent?

b) To what extent do undergraduate students enrolled in a Canadian university believe verbal consent always needs to be used during sexual encounters?

\section{Methods}

Qualitative research attempts to "make sense of or interpret the phenomena in terms of the meanings people bring to them" (Denzin \& Lincoln, 2011, p. 3). This approach was chosen to provide an in-depth exploration of UG students' beliefs around verbal consent, as qualitative methodologies allow rich descriptions of beliefs, values, and practices to be captured (Denzin \& Lincoln, 2011).

Qualitative research is steeped in core philosophical beliefs: Ontological, epistemological, and axiological beliefs (Creswell \& Poth, 2018). These elements were considered throughout this study. Ontological beliefs relate to the nature of reality and embracing multiple realities (Creswell \& Poth, 2018). Ontological beliefs were supported through the qualitative description design, as this allowed me to stay true to participants' words without high levels of interpretation, demonstrating the multiple perceptions held by 
participants. Epistemological beliefs focus on conducting the study in the field to understand participant context (Creswell \& Poth, 2018). Epistemological beliefs encourage the researcher to "minimize the distance between himself or herself and those being researched" (Creswell \& Poth, 2018, p. 21). This was achieved through my positionality in the research. I recently graduated from my UG program and am now a graduate student. I have first-hand knowledge of the socio-cultural complexities that exist on university campuses surrounding sexual consent. Finally, axiological beliefs centre around the researcher bringing their existing biases and values to the forefront and positioning themselves in their research based on social position and personal experiences (Creswell \& Poth, 2018). As a White, cisgender, heterosexual woman pursuing higher education, I recognize that my privilege and lived experience will influence how I interpreted the data. While this is acknowledged, it is not a limitation of the study, as qualitative research recognizes that the researcher's presence is inherent in the text just as much as the subject of study (Creswell \& Poth, 2018).

\section{Study Design}

Qualitative description was used for this study. Qualitative description provides insight on a topic that has not been previously studied by describing the phenomenon in the language used by the participants (Neergaard et al., 2009; Sandelowski, 2000). There has been virtually no research conducted examining verbal consent specifically, making qualitative description an ideal fit.

\section{Original Study and Participants}

This study used previously generated data that had been collected from a larger project but had not yet been analyzed. The original project, titled Educational Technology and Research Design: An exploratory mixedmethods study on predictors of undergraduate students' attitudes, opinions and beliefs on sexuality, was led by Dr. Matthew Numer and explored UG students' attitudes, opinions, beliefs, and practices around sex, gender, and sexuality. In the larger project, data was collected from UG students attending two similar-sized universities, one located in Canada and one located in the United States, enrolled in similar Human Sexuality courses; Data was collected using a mixed-method approach, employing two survey instruments and six open-ended questions requiring student's written responses. My study analyzed UG students' written responses to one of the openended questions: Do you believe sexual consent should always require verbal consent? Why/why not? Only Canadian data were used for this study, due to time constraints and capacity. The original study was provided with ethical approval by the Dalhousie Research Ethics Board. I submitted an amendment to the existing ethics to conduct this study for the fulfillment of the Bachelor of Science (Health Promotion) Honours degree program. Data used in this study was not included in the results of the original study.

\section{Recruitment, Data Collection and Data Analysis}

Recruitment for this study took place during the original project. Only the Canadian UG students recruited were included in this study. Students were enrolled and recruited from a Human Sexuality course. Data was collected using the required interactive course textbook, embedded into Top Hat. Top Hat is a web-based interactive education platform that offers instructors the ability to engage with their students electronically through classroom activities, course assignments, tests, and digital textbooks (Top Hat, n.d.). The open-ended questions were part of the course load for the class, so students were required to answer them; however, students were not obligated to have their responses used as part of the study. Thirty-one students consented to their responses being used for research purposes. Student responses to the one open-ended question were analyzed following the six-step process to thematic analysis outlined by Braun \& Clarke (2006). 


\section{Results}

Thematic analysis revealed four main themes on UG students' beliefs around verbal consent: Partner Familiarity, Social Norms, You Just Know, and Verbal is Ideal. I will describe each theme below and provide direct quotes from student's responses to provide justification.

\section{Partner Familiarity}

One of the most prevalent beliefs held by participants was that partner familiarity influenced verbal consent practices. Students repeatedly explained that verbal consent should be used if partners are not familiar with each other, such as in a new relationship or during first-time sexual encounters. One participant stated that "Verbal consent is important in newer relationships to lay out the mutual feelings of the partners." Similarly, one student explained that "If the relationship is new and the people involved aren't quite sure of the other person, verbal consent is something very important to establish." Students felt that verbal consent was crucial in new relationships to build trust between partners, as one student explained: "Sexual consent should be given in all first encounters and continued in early relationships until a trust is built between the partners and they can trust that what they are doing is accepted by the other."

Students also held the opinion that, in a relationship, partners should feel comfortable telling their partner no if they do not want to have sex, suggesting that consent was established based on the absence of no. One participant wrote that "If they do not want to have sex, they should feel comfortable enough in a long-term relationship to say so."

Participants explained that if two individuals are in a long-term, exclusive relationship, verbal consent is not always required. One participant commented:

You become familiar with your sexual partner when having been in a long term relationship and when it's not your first sexual encounter with that person. You become very aware of their body language, the things they enjoy or do not enjoy, and it becomes easily apparent whether they consent even if they don't verbally tell you.

Students also felt that in a long-term relationship there was an understanding of ongoing consent, causing students to believe that verbal consent was not required. For example, one participant wrote that "If you have an established sexual relationship with someone then I think there is the idea of an existing basis of consent to certain sexual activities."

\section{Social Norms}

Verbal consent was perceived as something that did not contribute to a comfortable sexual encounter. A barrier to using verbal consent was that it was perceived as awkward or uncomfortable, with one student commenting:

"I do not believe that sexual consent should always require verbal consent because it can ruin as moment." Another student stated that "it can be awkward for someone to be verbal when consenting but you can usually tell if they are okay or not okay with what is happening by nonverbal cues."

This quote demonstrates that students rely on non-verbal cues instead of verbal consent in an attempt to avoid social repercussions associated with using verbal consent.

Many students struggled with a negative perception of verbal consent because they felt that it was not perceived as attractive. Despite this, UG students also acknowledged the importance of verbal consent, which is exemplified by one student who wrote "I am torn on this as I believe [verbal consent] kills the mood but is also very important." Similarly, another student stated that "it is an unfortunate fact that not everyone finds [verbal consent] attractive." These quotes highlight that UG students acknowledge the importance of verbal consent, yet struggle with the social scripts of what is considered attractive and appropriate in sexual encounters.

Several students described attempting to combat the current negative perceptions of verbal consent by using alternative phrasing. 
For example, one student explained that "I don't think I've ever received a straight up 'yes' or 'no' from anyone regarding sex ... it's important to truly watch the other person ... how their body reacts ... a 'just like that' or a 'keep going'." This quote demonstrates that while students seek verbal reassurance of consent, they do not obtain verbal consent prior to sexual acts and instead rely on non-verbal cues. Many participants felt that using alternative phrasing when verbally asking for consent from their partner was more realistic and easier to achieve. One participant stated that "Sexual consent should always require some verbal element such as one person asking, 'do you want to?' or 'okay?'” This belief was shared by another student, who wrote "We all have certain behaviours that indicate we are interested in sexual acts, but I still [feel] that before starting a simple 'are you okay with this?' is not too hard." This quote demonstrates that UG students believe that using alternative phrasing makes verbal consent more accessible and easier to apply during sexual encounters. Similarly, another student stated the following:

Giving verbal cues may not seem like the most natural or easiest thing to do in such an intimate setting, but if both people verbally say they want to engage in a certain sexual act, then it is clear that both people are consenting and they both want to.

This student acknowledged that verbal consent is viewed negatively; however, this student also holds the belief that verbal consent ensures sexual activity is consensual, thus enhancing the experience of all partners. Despite this, the majority of UG students felt that obtaining consent via non-verbal cues was sufficient.

\section{"You Just Know"}

Verbal consent is typically lacking during UG students' sexual encounters. The primary method of obtaining sexual consent among UG students was non-verbal cues. Participants felt that verbal consent was not always required in sexual encounters, as many believed that a partner's non-verbal cues were sufficient in determining consent. As one student wrote:

"There is a clear difference between someone who is positively responding to sexual activity (making sounds, touching back, kissing back, moving with pleasure when being touched), compared with someone who has stiffened, stopped responding, etc."

Another participant shared a similar view, stating "There is a major difference between willing and resisting." Students emphasized examining body language and partner reciprocation to determine a partner's consent: "There are many other ways besides verbally to give your consent such as through smiling, nodding, or reciprocating the actions to your partner."

Students also wrote that they relied on non-verbal cues to determine if their partner was not comfortable: "You can usually tell if they are okay or not okay with what is happening by non-verbal cues such as trying to stop the other person or looking upset."

While the majority of participants felt that non-verbal cues provided a sufficient basis of consent, one UG student acknowledged the importance of being comfortable communicating concerns to their partner:

"I think that sexual consent does not always have to be verbal but it is important that individuals should be comfortable enough to verbally communicate if something is wrong."

While students felt that there were instances where verbal consent should be used, the majority of participants felt that non-verbal cues were sufficient in determining consent.

\section{Verbal is "Ideal"}

Students believed that they were expected to use verbal consent but did not seem to integrate it into their sexual encounters. One participant stated "I believe that in some cases verbal consent may not be needed. I say this with caution as most times verbal consent should be given." Another student wrote, "it is evident by body language when individuals are or aren't into 
it, yet there is no harm in verifying by asking your partner if they want to."

While the majority of students relied on non-verbal consent, several students fully endorsed the benefits of verbal consent and indicated that they believed it should be integrated into all sexual encounters. According to one participant, "I think verbal consent is the best way to give consent because I think communication is key. Even indirect verbal communication can lead to miscommunication in any situation so with regards to sex [verbal consent] is extremely important."

Similarly, another participant felt that using verbal consent in all sexual encounters ensures that both partners approve of what is happening and that the sexual activity is consensual. For example, one participant wrote the following:

Many people would take nonverbal cues to mean that consent has been given ... however this could lead to miscommunication, and possibly sexual activity where one party believes consent was given and the other does not. I think, in order to be safe and make sure both parties are fully engaged, verbal consent should always be given just to make sure that all parties engaging in the activity are on the same page.

\section{Discussion}

The purpose of this study was to explore UG students' attitudes, opinions, and beliefs around verbal consent. The findings highlight barriers to UG students integrating verbal consent into their sexual encounters and into the social norms that prevail on university campuses around sexual consent. There was a clear emphasis placed on relationship status, partner familiarity and use of verbal consent. This finding has been supported in prior research, showing that university students typically use verbal consent during first-time sexual encounters due to lack of familiarity but rely on non-verbal cues in long-term relationships (Marcantonio et al., 2018; Curtis \& Burnett, 2017). This remains concerning because $50 \%$ of reported cases of SA are perpetrated by someone known to the victim (Government of Canada, 2019).

Current perceptions of verbal consent among UG students show that verbal consent is considered awkward and uncomfortable. Prior research has demonstrated similar findings, showing that UG students avoid verbal consent due to the perceived embarrassment of both request and refusal (Curtis \& Burnett, 2017). Participants in this study stated that while these social norms persist, incorporating verbal consent more naturally by using alternative phrasing is a technique to combat the stigma. The negative perception of verbal consent is supported by both the media and peers, causing peers to often ridicule those who explicitly ask for verbal consent (Curtis \& Burnett, 2017). The findings of this study can support this concept, as the majority of participants stated that they did not believe verbal consent was required in all sexual encounters. Students believed that partners should be able to determine if a partner was willing or resisting sexual activity based solely on their physical cues. This finding supports other research that has found that UG students typically rely on non-verbal cues due to the common belief that "you just know" when a partner is consenting (Curtis \& Burnett, 2017). Despite this, many students understood the benefits of verbal consent and stated that verbal consent caused fewer misinterpretations; however, these beliefs were often contradicted by students' beliefs that a partner's physical cues would clearly indicate their consent.

\section{Conclusion \& Recommendations}

The findings of this study show that UG students view the need for verbal consent as contextual, based on a number of factors. A key takeaway from this study was that UG students' beliefs and practices around verbal consent may contradict each other due to social norms and pressures. The current social environment on university campuses surrounding verbal consent is harming the health of UG students by contributing to the unrelenting rates of SA. Based on the findings of this study, it is clear that the current stigma and social perception of 
verbal consent needs to be considered when addressing SA on university campuses. Campus interventions should be created to shift perceptions of verbal consent in a way that is meaningful and relevant to this population. Examples may include social media campaigns that promote verbal consent or student-led initiatives that start conversations around verbal consent.

\section{Implications \& Future Research}

The findings of this research contribute to two core competencies of the Healthy Populations Institute: Agents of change and research, policy, and practice (Miller et al., 2021). These findings can be used to shift universities' socio-cultural environments to reduce institutionalized support of SA. The findings could also help strengthen campus policies and practices around sexual consent to combat the SA epidemic.

Future research should consider whether characteristics such as gender, sexual orientation, age, or discipline influence UG students' beliefs around verbal consent. Further, a similar study using discourse analysis should be conducted to examine the interactions between beliefs, practices, social position, and relations of power.

\section{References}

Braun, V., \& Clarke, V. (2006). Using thematic analysis in psychology. Qualitative Research in Psychology, 3(2), 77-101. https://doi.org/10.1191/1478088706q p063oa

Creswell, J. W., \& Poth, C. N. (2018). Qualitative inquiry and research design: Choosing among five approaches ( $4^{\text {th }}$ ed.). Sage Publications.

Criminal Code, RSC 1985, c. C-46, s. 271.1 (1).

Criminal Code, RSC 1985, c. C-46, s. 273.1 (1).

Curtis, J. N., \& Burnett, S. (2017). Affirmative consent: What do college student leaders think about "yes means yes" as the standard for sexual behavior? American Journal of Sexuality
Education, 12(3), 201-214. https://doi.org/10.1080/15546128.20 17.1328322

Daigle, L. E., Johnston, T., Azimi, A., \& Felix, S. N. (2019). Violent and sexual victimization among American and Canadian college students: Who is more at risk and are the risk factors invariant? Journal of School Violence, 18(2), 226-240. https://doi.org/10.1080/15388220.20 18.1459631

Denzin, N. K., \& Lincoln, Y. S. (Eds.). (2011). The Sage handbook of qualitative research (4th ed.). Sage.

Government of Canada (2019). JustFacts: Sexual assault. Department of Justice. https://www.justice.gc.ca/eng/rp$\mathrm{pr} / \mathrm{jr} / \mathrm{jf}-\mathrm{pf} / 2019 /$ apr01.html

Gray, J. M. (2015). What constitutes a "reasonable belief" in consent to sex? A thematic analysis. Journal of Sexual Aggression, 21(3), 337-353. https://doi.org/10.1080/13552600.20 14.900122

Hermann, C., Liang, C. T. H., \& DeSipio, B. E. (2018). Exploring sexual consent and hostile masculine norms using the theory of planned behavior. Psychology Of Men \& Masculinity, 19(4), 491-499. https://psycnet.apa.org/doi/10.1037/ men0000127

Jozkowski, K. N., Manning, J., \& Hunt, M. (2018). Sexual consent in and out of the bedroom: Disjunctive views of heterosexual college students. Women's Studies in Communication, 41(2), 117139. https://doi.org/10.1080/07491409.20 18.1470121

Jozkowski, K. N., \& Peterson, Z. D. (2013). College students and sexual consent: Unique insights. Journal of Sex Research, 50(6), 517-523. https://doi.org/10.1080/00224499.20 12.700739

Jozkowski, K. N., Peterson, Z. D., Sanders, S. A., Dennis, B., \& Reece, M. (2014). Gender differences in heterosexual college students' conceptualizations and 
indicators of sexual consent:

Implications for contemporary sexual assault prevention education. The Journal of Sex Research, 51(8), 904-916. https://doi.org/10.1080/00224499.20 13.792326

Marcantonio, T., Jozkowski, K. N., \& WiersmaMosley, J. (2018). The influence of partner status and sexual behavior on college women's consent communication and feelings. Journal of Sex \& Marital Therapy, 44(8), 776-786. https://doi.org/10.1080/0092623X.20 18.1474410

Marcantonio, T. L., Jozkowski, K. N., \& Lo, W.-J. (2018). Beyond "Just saying no": A preliminary evaluation of strategies college students use to refuse sexual activity. Archives Of Sexual Behavior, 47(2), 341-351. https://doi.org/10.1007/s10508-0171130-2

Miller, L., Brushett, S., Ayn, C., Furlotte, K., Jackson, L., MacQuarrie, M., Massie, A. S., Mathias, H., McKay, M., Meisner, B. A., Moritz, L., Stilwell, C., \& Weeks, L. E. (2021). Developing a competency framework for population health graduate students through student and faculty collaboration. Pedagogy in Health Promotion, 7(3), 280-288. https://doi.org/10.1177\%2F23733799 19859607

Neergaard, M. A., Olesen, F., Andersen, R. S., \& Sondergaard, J. (2009). Qualitative description - the poor cousin of health research? BMC Medical Research Methodology, 9, Article 52. https://doi.org/10.1186/1471-2288-952

Potter, S., Howard, R., Murphy, S., \& Moynihan, M. M. (2018). Long-term impacts of college sexual assaults on women survivors' educational and career attainments. Journal of American College Health, 66(6), 496-507. https://doi.org/10.1080/07448481.20 18.1440574
Pugh, B., \& Becker, P. (2018). Exploring definitions and prevalence of verbal sexual coercion and its relationship to consent to unwanted sex: Implications for affirmative consent standards on college campuses. Behavioral Sciences, 8(8), Article 69. https://doi.org/10.3390/bs8080069

Quinlan, E., Clarke, A., \& Miller, N. (2016). Enhancing care and advocacy for sexual assault survivors on Canadian campuses. Canadian Journal of Higher Education, 46(2), 40-54. https://doi.org/10.47678/cjhe.v46i2.1 85184

Sandelowski, M. (2000). Focus on research methods: Whatever happened to qualitative description? Research in Nursing \& Health, 23(4), 334-340. https://doi.org/10.1002/1098240X(200008)23:4\%3C334::AIDNUR9\%3E3.0.CO;2-G

Senn, C. Y., Eliasziw, M., Barata, P. C., Thurston, W. E., Newby-Clark, I. R., Radtke, H. L., Hobden, K. L., \& SARE Study Team (2014). Sexual violence in the lives of first-year university women in Canada: No improvements in the 21st century. BMC Women's Health, 14, Article 135. https://doi.org/10.1186/s12905-0140135-4

Top Hat (n.d.). Top Hat Classroom. https://tophat.com/classroom/

United Nations (n.d.). Goal 5: Achieve gender equality and empower all women and girls. https://www.un.org/sustainabledevelo pment/gender-equality/

World Health Organization (2012). Understanding and addressing violence against women: Sexual Violence. https://apps.who.int/iris/bitstream/ha ndle/10665/77434/WHO_RHR_12.37_e ng.pdf;jsessionid=1B7DA2157511B30D 07141C4561F4B03E?sequence $=1$ 